\title{
Antenatal Radiological Diagnosis of Rare Case of Dicephalus Dipus Dibrachius and Its Correlation with the Abortus
}

\author{
Sherwani $\mathbf{P}^{1,2}$, Singh $\mathbf{P}^{1}$, Singhla $\mathbf{V}^{1}$, Khandelwal $\mathbf{N}^{1}$ \\ ${ }^{1}$ Department of Radiodiagnosis, Post Graduate Institute of Medical Education and Research \\ Center (PGIMER), Chandigarh, Punjab, ${ }^{2}$ Lady Harding Medical College and associated \\ Hospitals, Delhi, India
}

\begin{abstract}
Dicephalus twins are an extremely rare type of conjoined twins. Early prenatal diagnosis of this condition is important to provide an opportunity for pregnancy termination. We present such a case which was diagnosed by ultrasound \& MRI examination at 18 weeks of gestation and is confirmed after therapeutic abortion with the abortus.
\end{abstract}

Keywords: Conjoined twins, Dicephalus, Prenatal diagnosis, Ultrasound.

\section{Introduction}

Conjoined twins are extremely rare and have an estimated incidence ranging from $1: 50,000$ to $1: 100,000$ live births. ${ }^{1}$ In dicephalus dipus dibrachius, there are two heads, two arms and two legs. ${ }^{2}$ The mechanism of the development of dicephalus conjoined twinning is splitting of the embryo only in the cephalic region. Early radiological detection of these fetuses is important as careful sonographic evaluation is warranted to look for associated anomalies and to counsel the parents for the termination of pregnancy. Our case is unique as it had solitary non duplicated spine and also concurrent diaphragmatic hernia.

Corrospondence to: Dr Poonam Sherwani, Department of Radiodiagnosis, Lady Harding Medical College and associated Hospital, New Delhi-110001, India. E-mail:- Poonam_doc2003@yahoo.co.in

\section{Case Report}

A healthy 23 year old female Gravid 2 Para 1 was referred to the radiology department at 18 wks of gestation for sonographic evaluation of congenital malformation in the fetus. Her personal and medical history was unremarkable and there was no history of drug intake during pregnancy. A transabdominal ultrasound scan was done on Philips HD 11 machine using $3.5 \mathrm{MHz}$ Curvilinear array transducer. The fetus revealed two heads, one trunk, two arms and two legs and the heads were fused in the occipital region. The brain in each calvaria was normal except for ventriculomegaly (Fig.1a). There was a single spine and left sided diaphragmatic hernia with stomach as the herniating content (Fig.1b). The placenta was upper anterior and liquor was normal. Magnetic Resonance imaging (MRI) was performed for detailed evaluation of brain anatomy and spine especially that of 


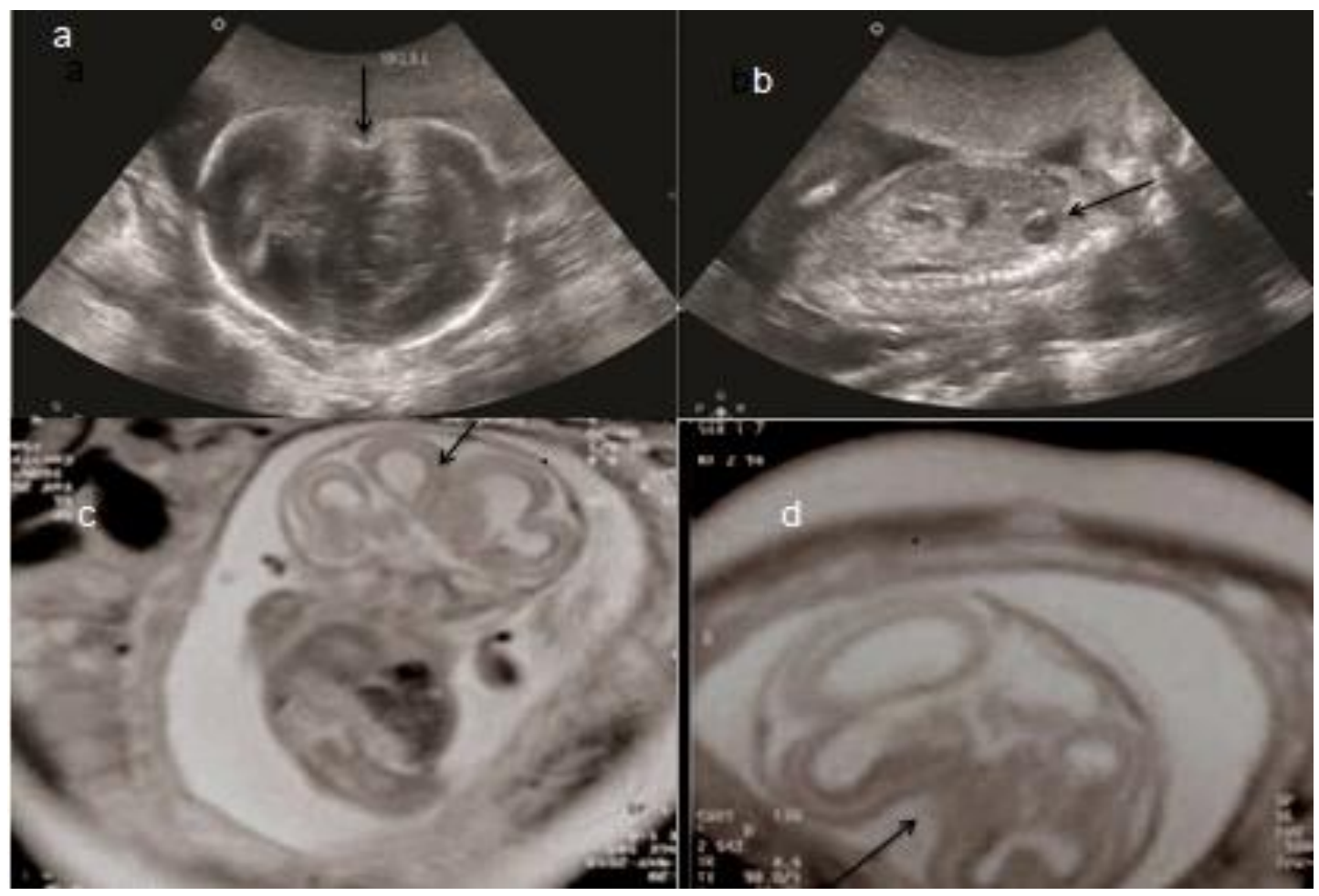

Fig. 1(a) Real time sonographic images showing two fused skulls (arrow) and hydrocephalus (b) Fetal sagittal ultrasound showing stomach (arrow) thorax and single trunk. (c) Coronal MRI images (Haste Sequence) showing two fused fetal brains (arrow) with dilated ventricles and single trunk. (d) Axial MR view of fetal brain depicting fused brains with ventriculomegaly.

posterior fossa which confirmed the above forementioned findings (Fig.1c \& Fig.1d). After prognosticating the parents about the poor chances of survival after surgical correction, termination of pregnancy was performed with misoprostol and oxytocin.

The postnatal photograph of the abortus confirmed depicted features which revealed two fused heads and two faces with single trunk, two arms and legs (Fig.2a \& 2b).

\section{Discussion}

Conjoined twins are monochorionic monoamniotic twins and result due to incomplete division of the embryonic disk between 13 to 15 days after fertilisation. ${ }^{1}$ The etiology is unknown, does not vary with maternal age and risk of recurrence in subsequent pregnancies does not exist. Conjoined twins are classified into Terata catadidymia, terata anadidyma, terata ancatadidyma according to anatomical sites of incomplete separation. ${ }^{2}$ The terata catadidymia group includes dicephalus kind of twins which have two heads and one body. Dicephalus dipus dibrachius is one of its least frequent variants in which the fetus has two heads, one trunk, two upper and two lower limbs. In dicephalus twins, the spine may show duplication to varying degree although externally the body may appear single. ${ }^{3}$

Prenatal diagnosis of conjoined twins is of utmost importance and ultrasonographic criteria include bifid appearance of fetal pole in the first trimester, absence of separating membrane, heads or bodies at the same 


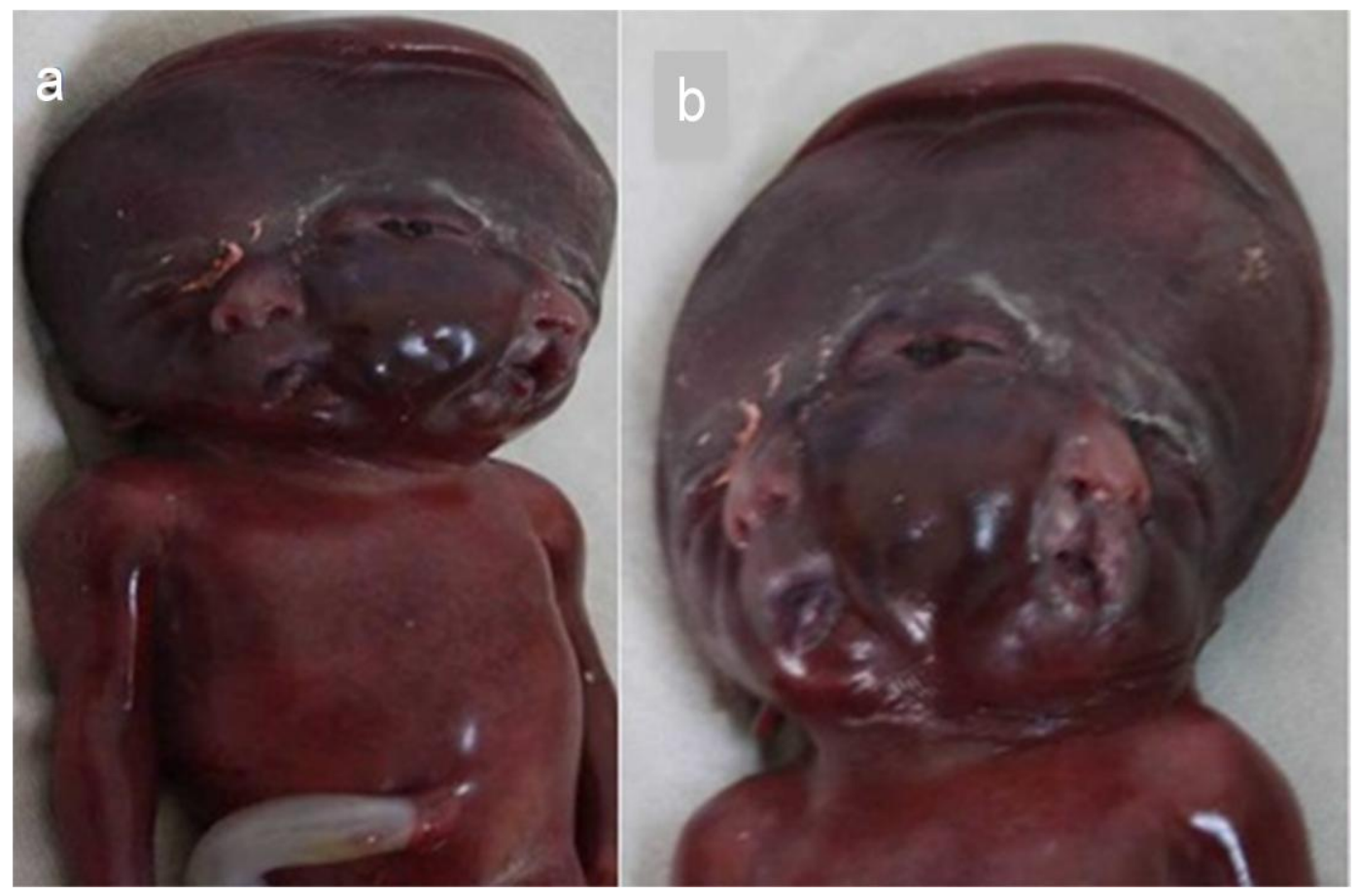

Fig. 2a \& b: Photographs of the abortus confirming the imaging findings of two fused skulls and faces with single body.

level, absence of change in relations of body parts despite change in fetal position, unusual proximity of extremities and more than three vessels in the umbilical cord. ${ }^{4}$

Prognosis of conjoined twins is guarded as there is fusion of organs so separation of dicephalus dipus dibrachius twins should not be attempted. ${ }^{5}$

\section{Conclusion}

In conclusion, this case highlights rare anomaly of conjoined twins and the significance of diagnostic imaging which aids in early management and termination of pregnancy.

\section{References}

1. Dskalatis G, Pilalis A, Tourikis. First trimister diagnosis of dicephalus conjoined twins. Eur J obstet Gynecol reprod. Biol 2004;112(1):110-1132.
2. Golladay ES, Doyne Williani G, Sibut JJ. Dicephalus dipus conjoined twins: A surgical separation \& review of previously reported cases. J Pediatric Surg 1982;17:250-264.

3. Balakumar K. Antenatal ultrasound diagnosis of dicephalus dipus dibrachius and its correlation with autopsy. IJRI 2006;16:1:107-108.

4. Tongson T, Chanprapaph P, Pongsatha S. First trimester diagnosis of coinjoined twins:a report of three cases .Ultrasound Obstet Gynecol 1999;14:434-7.

5. Aparna C, Renuka IV, Sialabala G. Nayudamma Y. Dicephalus dipus tribrachius: A case report of unusual coinjoined twins. Indian journal of Pathology and Microbiology 2010;53(4):814-816. 